This is the final peer-reviewed accepted manuscript of:

Mancini, G. Trait Emotional Intelligence and Draw-A-Person Emotional Indicators: a First Study on 8-Year-Old Italian Children. Child Ind Res 12, 1629-1641 (2019).

The final published version is available online at:

https://doi.org/10.1007/s12187-018-9601-0

Rights / License:

The terms and conditions for the reuse of this version of the manuscript are specified in the publishing policy. For all terms of use and more information see the publisher's website. 
Trait Emotional Intelligence and Draw-A-Person Emotional Indicators: A First Study on 8Year-Old Italian Children

\author{
Giacomo Mancini
}

Corresponding author:

Giacomo Mancini, Alma Mater Studiorum (University of Bologna) Department of Education - via Filippo Re 6, 40126 - Bologna Italy - E-mail address: giacomo.mancini7@ unibo.it

The author declares that there are no external or grant funding of the work.

The author declares that he has no competing or potential conflicts of interest.

The author is grateful to Prof. Stefano Passini for statistical advice and to Dr. Federica Vignoli for her assistance in data collection. 
1

12

2

33

$6^{4}$

7

85

9

106

11

127

13

14

$15^{8}$

16

179 18

1910

20

21

$22^{11}$

23

2412

25

26

$27^{13}$

28

2914

30

$31^{3} 15$

33

34

35

36

37

38

39

40

41

42

43

44

45

46

47

48

49

50

51

52

53

54

55

56

57

58

59

60

61

62

63

64

65
Trait Emotional Intelligence and Draw-A-Person Emotional Indicators: A First Study on 8-YearOld Italian Children

$$
\text { Author }
$$

Institution 
Abstract

Scholars have shown the link between trait emotional intelligence (EI) and psychological health in adults, as well as in children, together with a strong association of the construct with expression of emotions, which may be well represented by children's drawings. This work focuses on the effects of trait EI on Koppitz's emotional indicators in the Draw-a-Person (DAP) test, a projective drawing task that is often used in psychological assessments of children to develop hypotheses about the subject's cognitive, developmental, and emotional functioning, as well as personality style. Given the link between a child's graphic activity and the expression of emotions, we assume that trait EI can be a reliable predictor of emotional expression revealed by the DAP test, over and above personality traits. A self-report form to assess trait EI, a personality questionnaire, and the DAP test were administered to a sample of 82 Italian children $(51.2 \%$ females; Mage $=8.11 ; S D=0.35)$. Data from hierarchical regression analysis suggest a predictive significant effect of trait EI on emotional indicators in children's drawings $(\beta=.36, p$ $<.05)$. Future investigations should replicate these results in larger samples and in cross-cultural settings. Notwithstanding these limitations, this work may provide a springboard for developing new lines of research on the influence of trait EI on children's drawings, considering the internal representation related to emotional expression to be paramount. Moreover, our results may have practical implications, particularly with respect to programs and policies addressing the prevention of emotional distress in children.

Keywords: trait emotional intelligence, Draw-a-Person test, childhood, emotional expression, psychological well-being 
Trait Emotional Intelligence and Draw-A-Person Emotional Indicators: A First Study on 8-Year-

\section{Old Italian Children}

Emotional intelligence (EI), the latest theoretical outcome of the emotion-reason debate,

is defined in broad terms as the competence of individuals to recognize their own emotions and those of others, discern between different emotional conditions and label them appropriately, use emotional information to address thinking and behaviour, and regulate emotions to adapt to environments or achieve their goals (Andrew, 2008). EI also reflects the ability to join intelligence, empathy, and emotions to improve thoughts and understanding of interpersonal dynamics (Mayer, 2008). From this point of view, EI represents an expression of the progressive emphasis of the scientific literature on the significance of emotion-related competencies or dispositions in successful adaptation.

Scholars have categorized several models of EI (ability, trait, and mixed-models) that have led to the development of many instruments for the assessment of the construct. Two main constructs of EI should be distinguished based on the measurement method used in the operationalization process (self-report or maximum-performance): trait and ability EI (see Petrides \& Furnham, 2000, 2001, 2003). Trait EI (or trait emotional self-efficacy) concerns emotion-related dispositions and self-perceptions measured via self-report, whereas ability EI (or cognitive-emotional ability) concerns emotion-related cognitive abilities that ought to be measured via maximum-performance tests. The conceptual differences between the two constructs (see Petrides, Furnham, \& Frederickson, 2004) are directly reflected in empirical findings, which reveal very low, often nonsignificant, correlations between measures of trait and ability EI, thereby supporting an explicit distinction between the constructs (Petrides, Furnham, \& Mavroveli, 2007).

Despite the current debate on the consensus and controversies in relation to some main concerns of EI research (i.e., conceptualization, assessment, and applications; Zeidner, Roberts, \& Matthews, 2008), EI remains an important construct to investigate, especially among young 
people, due its potential to predict social (e.g., Zeidner \& Matthews, 2016), educational (e.g.,

Fernandez-Berrocal \& Ruiz, 2008; Mancini et al., 2017), health care (e.g., Martins, Ramalho, \&

Morin, 2010), and clinical (e.g., Resurrección, Salguero, \& Ruiz-Aranda, 2014) criteria.

\section{Trait Emotional Intelligence}

As mentioned above, among the different theoretical models, the approach developed by

Petrides and Furnham $(2000,2001)$ aimed at systematizing the conceptualization of trait EI: the operationalization of EI as a personality trait, which has emerged as the dominant approach to the study of EI. According to Petrides Pita and Kokkinaki (2007), trait EI is a constellation of emotional self-perceptions located at the lower levels of personality. Overall, this definition

basically states that trait EI concerns how people perceive their own emotional and social effectiveness and that the trait EI sampling domain aims to provide comprehensive coverage of the emotion-related aspects of personality. This definition of EI involves behavioural dispositions and self-perceived emotional abilities and is evaluated by self-report. Moreover, trait EI theory is consistent with established individual differences theories: It lies wholly outside the realm of cognitive ability and can be integrated into hierarchical models of personality. Namely, trait EI should be investigated within a personality framework (Petrides \& Furnham, 2001).

Indeed, trait emotional self-efficacy is explicitly conceptualized as a personality trait, and therefore, trait EI is expected to be part of the major personality taxonomies, such as the Big Five (Costa \& McCrae, 1992), rather than distinct and independent of them (see Andrei, Mancini, Baldaro, Trombini, \& Agnoli, 2014; Pérez-González \& Sanchez-Ruiz, 2014). The Big Five personality traits is a model based on common language descriptors of personality and therefore suggests five broad dimensions commonly defined as Neuroticism, Extraversion, Openness to Experience, Agreeableness, and Conscientiousness. Under each global factor, there are a number of correlated and more specific primary factors (Goldberg, 1993). Findings to date suggest that individual differences in trait EI are a reliable predictor of human behaviour throughout a lifetime. Petrides et al. (2016) provided a comprehensive overview of research findings relating 
to trait EI. The main part of the findings indicate that trait EI is beneficial in various domains, such as clinical, health, social, educational, and organizational (Schutte \& Malouff, 2016).

\section{Trait Emotional Intelligence in Children}

In line with related research on adults, trait EI has also been studied in childhood, through the use of the TEIQue-Children Form (TEIQue-CF), the only instrument based on a sampling domain that has been specifically developed for children aged between 8 and 12 years

(Mavroveli, Petrides, Shove, \& Whitehead, 2008). The TEIQue-CF comprises 75 items, clustered into 9 distinct facets, and rated on a 5-point scale (e.g., "Usually, I'm in a bad mood" and "If someone makes me angry, I tell them"). Research involving children has pointed out that trait EI appears to be an important predictor of health-related outcomes (such as well-being and social interactions) throughout development (Andrei et al., 2014). For instance, high levels of trait EI are associated with fewer somatic complaints in children (e.g., Jellesma, Rieffe, Meerum Terwogt, \& Westenberg, 2011). Moreover, trait EI is highly impaired in children with attention deficit hyperactivity disorder (Abo Elella et al., 2017). Most research involving pupils has been carried out in schools, with results showing that individual differences in trait EI may be relevant to a positive adaptation within the scholastic context, with particular implications for socioemotional competence and behaviour (Frederikson, Petrides, \& Simmonds, 2012). For instance, Petrides, Frederickson, and Furnham (2004) demonstrated that pupils with high trait EI were less likely to be expelled from school and to have had unauthorized absences. Additionally, it seems that peer nominations for prosocial behaviours are associated with high trait EI, as assessed by the TEIQue-CF (Mavroveli, Petrides, Sangareau, \& Furnham, 2009). Self-reported data revealed that higher scores on the TEIQue are negatively related to bullying behaviours (Mavroveli \& Sanchez-Ruiz, 2011), victimization (Kokkinos \& Kipritsi, 2012), and fewer behavioural difficulties more generally (Poulou, 2014). The scientific literature shows that individual differences in trait EI may influence academic achievement. Even though a univocal and direct pattern of association between the TEIQue scores and school performance has not 
always been proved (Agnoli et al., 2012; Hansenne \& Legrand, 2012; Mavroveli et al., 2009;

Mavroveli et al., 2011), trait EI could serve as a moderating factor between intelligence and scholastic achievement.

\section{Children's Drawing as an Emotional Indicator}

These data highlight the strong relationship between trait EI and emotional regulation and expression (Laborde, Lautenbach, Allen, Herbert, \& Achtzehn, 2014), which in children are areas closely related to health and psychological well-being. Emotional regulation, which refers broadly to implementation of a conscious or unconscious aim to start, stop, or otherwise modulate the trajectory of an emotion (Gross, 2015), is a crucial determinant of behaviour, thought, and experience, mainly in children, in their different ways of expressing themselves. Children frequently share their emotions through drawing, which, since the earliest developments in psychology, has been considered a useful tool for understanding both the child's intellectual maturation and personality. Because of the importance of graphic expression in the child's daily life and its easy administration, psychologists have constructed graphical tests as tools to gain knowledge of the child's emotional and interpersonal world. In particular, one of the most significant is the test of the human person (Buck, 1948, 1981; Levy, 1950; Machover, 1953), which as a whole reflects the emotional experiences, self-esteem, organization, and selfimage of the individual, in light of the scientific status of projective techniques (Lilienfield, Wood, \& Garb, 2000). Developed originally by Florence Goodenough in 1926, the Draw-aPerson test (DAP test, or Goodenough-Harris Draw-a-Person test) is a projective drawing task that is often used in psychological assessments of children. It has guidelines for assessing youths from ages 6 to 17 (Scott, 1981). The test has been revised many times, with supplementary measures for assessing intelligence (Weiner \& Greene, 2008). Although there are a number of variations, an individual is typically asked to draw a picture of a person, which is then evaluated on a number of dimensions. Results are analysed to develop hypotheses about the subject's cognitive, developmental, and emotional functioning, as well as personality style. 
Since the DAP test was created, other researchers have developed personality or cognitive tests using the child's drawing of the human figure. For instance, in 1949, Karen

Machover developed the first measure of figure drawing as a personality assessment with the DAP test, using the tool to assess people of all ages. Machover (1949) used a qualitative approach in her interpretation, considering individual drawing characteristics. Others (e.g., Buck, 1948) have suggested a more quantitative approach that can be more widely used by analysing selected characteristics that are an index of deeper meanings (Murstein, 1965). In 1968, Koppitz was the first to systematically examine the human figure drawings of children aged 5-12 years for developmental and emotional signs and symbols, providing a new and different method for the interpretation of the DAP test. Scoring for items considered "exceptional" and "expected" based on age-related normative data, to arrive at a broad score of intellectual and emotional functioning, she devised a list of emotional indicators such as size of figures, omission of body parts, placement of the arms, inclusion of shading, asymmetry, transparency, and so on. The total number of indicators is simply added up to provide a number that represents the likeliness of disturbance, or which is thought to reveal a range of personality traits and reflect the emotional maturity and psychological health of the child (for a content analysis of human figure drawings, see Skybo, Ryan-Wenger, \& Su, 2007). These were based originally on Machover (1953), Hammer (1958), and Koppitz's (1968) own clinical experiences, albeit given a more empirical basis (Thomas \& Jolley, 1998). Total scores of emotional indicators were found to be higher in clinical populations (Koppitz, 1968).

\section{Study Purpose}

The present study aimed to investigate the effect of trait EI, measured via the TEIQue$\mathrm{CF}$, on the adequacy of emotional indicators in children's human figure drawings. The effect of trait EI on the DAP test was examined in a sample of primary school children, considering both the global construct's composite and the role of the five major personality traits from the Big Five model. It was expected to find a positive effect of both the Big Five factors (Extraversion, 
Agreeableness, Conscientiousness, Emotional instability, and Mind Openness) and trait EI on

children's human figure drawings. Specifically, it was assumed that the trait EI effect on emotional indicators in the DAP test would explain this prediction above and beyond personality traits, as measured by the Big Five Questionnaire (BFQ).

\section{Methods}

\section{Participants}

A convenience sample of 98 children (51.2\% females, $48.8 \%$ males) participated in the current study, conducted in an urban school district between May and June 2017. The participants were recruited in a state primary school (third grade) in the town of Bologna (North Italy). Participants came from predominantly, but not exclusively, White, middle-class backgrounds. The ethnic composition of the sample was solely Italian. Pupils with special educational needs $(n=7)$, those who spoke Italian as an additional language $(n=8)$, and children with missing data $(n=1)$ were excluded from subsequent analyses. Complete data were available for 82 pupils (42 females) ranging in age from 8 to 9 years old $(M=8.11 ; S D=0.35)$.

\section{Measures}

The Big Five Questionnaire-Children (BFQ-C; Barbaranelli, Caprara, Rabasca, \& Pastorelli, 2002) is a 65-item questionnaire developed to measure the Big Five factors in children and adolescents. Each Big Five factor was measured by means of 13 items for each of the five dimensions of Energy (which resembles the dimension of Extraversion), Agreeableness,

Conscientiousness, Emotional Instability, and Openness. The items are rated according to occurrence frequency on a 5-point Likert-type scale, ranging from 1 (Almost never) to 5 (Almost always). Raw scores were transformed into T scores according to age normative tables (see Barbaranelli et al., 2002). The reliability of the scales, calculated using Cronbach's alpha coefficient, was found to comply with the standard criteria of acceptability (Pedhazur \& Pedhazur Schmelkin, 1991). In particular, they were: Energy = .66, Agreeableness $=.78$, Conscientiousness $=.75$, Emotional Instability $=.79$, and Openness $=.76$. 
The TEIQue-CF (Mavroveli et al., 2008) is a self-report inventory developed after a content analysis of the literature on children's socioemotional development. The TEIQue-CF comprises 75 short statements (e.g., "It's easy for me to show how I feel") responded to on a 5point Likert-type scale, ranging from completely disagree to completely agree. The English version of the TEIQue-CF demonstrated satisfactory levels of internal consistency $(\alpha>.72)$ and temporal stability over a 3-month interval ( $r=0.79$; Mavroveli et al., 2011; Mavroveli et al., 2008). In the present study, we used the Italian version of the TEIQue-CF (see Russo et al., 2012 for psychometric properties), prepared with a graphic layout appropriate to the respondents' age. For each participant, a score for the global trait EI was computed. The Cronbach's alpha of the global TEIQue-CF score was .84.

The DAP (Goodenough, 1926) is a projective drawing task that is often used in cognitive, developmental, and emotional assessments of children. Test administration involves the researcher requesting children to complete an individual drawing: The child is given an $8.5 \times 11$ inch blank piece of paper and a No. 2 pencil and is instructed to "Draw one whole person. You can draw any kind of person you want to draw, but not a stick figure” (Koppitz, 1984, p. 10). No further instructions are given, and the child is free to make the drawing in whichever way he or she would like, so there is no right or wrong type of drawing. While the test has no time limit, children rarely take longer than about 10 or 15 minutes to complete the drawing. The test is completely noninvasive and nonthreatening to the children, which is part of its appeal. Drawings can be assessed for developmental level and evidence of emotional indicators. Original Koppitz (1968) emotional indicator scores were considered. To evaluate these indicators, two independent, experienced, and trained judges assessed each drawing through a quantitative/qualitative scoring system. Specifically, in agreement with Koppitz (1968), 15 different aspects of the drawings (such as specific body parts, including presence or absence, detail, and proportion) were considered for a total final score. The internal reliability was .61.

\section{Procedure}


The present research was approved by the Ethical Committee of the Department of

Educational Sciences. The purpose of the study was presented to the school principals and teachers. Parents gave their written consent for the study, and children were freely allowed to participate in, or abstain from, the research. All measures were administered collectively within classrooms, at a time agreed on with the institute, by a specialized researcher and in compliance with the law on data privacy. Data collection occurred during class time: Children were first given the BFQ-C and, subsequently, the TEIQue-CF, after brief group guidelines were provided regarding the answer formats. Questionnaires were administered according to standard instructions as a group test and without any time limits. However, administration lasted between 30 and 35 minutes. Finally, all participants were given the DAP test: All children filled out the drawing task individually, taking a maximum of 15 minutes.

\section{Data Analyses}

Statistical analyses were conducted using IBM SPSS Statistics for Windows, version 19.0 (IBM Corp., Armonk, N.Y., USA). First, correlations were inspected in order to consider the relationships between all the variables. Then, to evaluate the contribution of trait EI in the prediction of emotional indicators, a stepwise hierarchical regression was performed with DAP scores as the dependent variable. The Big Five factors were entered at Step 1 and the trait EI at Step 2 to investigate the incremental validity of trait EI beyond the Big Five.

\section{Results}

Correlations between the key variables in the study are given in Table 1. Trait EI was related to all of the Big Five factors. In particular, trait EI was strongly related to

Conscientiousness and Agreeableness and, in the opposite direction, to Emotional Instability.

Significant positive associations also emerged between DAP emotional indicators and both trait EI and Conscientiousness, while no correlation occurred between DAP and the others four BFQ-

C dimensions. 
Then, the regression effect of DAP on the relationship between trait EI and personality traits was analysed. Hierarchical regression analysis was computed, with DAP as the dependent variable and the Big Five factors (Step 1) and trait EI (Step 2) as the predictors. As shown in Table 2, in Step 1, the only significant predictor was Conscientiousness $(\beta=.30, p<.05)$. The other factors were not significant. In Step 2, trait EI was a significant predictor $(\beta=.36, p<.05)$, and trait EI increased the proportion of variance explained. Moreover, the prediction effect of the Big Five decreased and was no more significant when trait EI was entered into the model.

\section{INSERT TABLE 2 HERE}

\section{Discussion}

The aim of the present research was to analyse the effects of trait EI on the emotional indicators of children's drawings in the DAP test. Given the link between children's graphic activity and the expression of emotions, this work focused on the drawing test of the human person as an expressive area intrinsically linked to personality and emotional domains, as described by trait EI. As previously noted, trait EI is a constellation of emotional perceptions assessed via questionnaires and rating scales (Petrides et al., 2007) and essentially concerns people's perceptions of their emotional world. That is, the trait EI sampling domain aims to provide comprehensive coverage of the emotion-related aspects, which integrates a range of affective facets of personality. In line with research on adults (e.g., Petrides et al., 2007), data from this study highlighted the associations between trait EI and the Big Five personality factors. This result is part of the discussion, already widely reported in the literature, on the partial or total overlapping of trait EI with personality. Indeed, a criticism levelled against the conceptualization of EI as a personality trait is that it overlaps considerably with the higher order personality dimensions and, therefore, has weak utility. In a recent meta-analysis (van der Linden et al., 2018), findings suggest that the general factor of personality is a social effectiveness factor very similar to trait EI. However, on the other hand, a systematic review and meta-analysis of the incremental validity of trait EI as operationalized through the TEIQue 
(Andrei et al., 2016) showed that trait EI emerged as a statistically and practically significant incremental predictor of multiple psychological variables beyond the higher order personality dimensions (i.e., the Big Five) and specific individual difference variables (e.g., alexithymia and social desirability). In relating these concerns (which, however, refer to the adult population) to the data of the present study, it has to be noted that the overlap between the TEIQue and some dimensions of the Big Five might influence the multicollinearity in the regression results. However, data on this sample of children reveal a moderate and not a large or total correlation between the two instruments, indicating that trait EI may be considered a distinct and compound construct that lies at the lower levels of personality hierarchies (Petrides et al., 2016). Further assessments of the predictive utility of the TEIQue-CF should consider children's populations.

The only significant correlation emerged between DAP score and Conscientiousness, while the other BFQ dimensions were not significant. This result is partially surprising because it was expected that the drawing of the human figure, alongside an ideal instrument for selfexpression, and of the emotional and relational area of the child, would also reveal information about some of these personality features, and for this reason, it is used as projective drawing technique in psychological assessments (Thomas \& Jolley, 1998). A possible explanation is that the setting of the test administration influenced the results to a certain extent in this respect. Indeed, it is of great importance to consider the difference between clinical and educational settings. In the clinical situation, the emotional relationship between the psychologist and the young patient and the specific expectation of the latter to receive help could elicit more information about the child's personality (such as Extroversion or Neuroticism) through the drawing test. The DAP was applied here in a class-group administration, in the presence of teachers, and for research purposes. Such school/research specificities can lead children to focus on the executive aspects of the task and amplify its accuracy, with the intention of looking like devoted and diligent pupils. In the school environment, it would be considered beneficial to have high standards of study and behaviour; to be more organized, thorough, persistent, and 
meticulous; and to follow instructions correctly. Therefore, in contrast with the impact of other personality traits, only Conscientiousness showed a significant and quite robust relationship.

The most relevant data of the present research seem to be that trait EI is positively related with emotional indicators in the DAP test, a result that was confirmed by its predictive effect in the hierarchical regression. Moreover, when trait EI was inserted in the regression analysis, the effect of the Big Five was no longer significant. Even though the relatively low $R^{2}$ value should lead to handling the results with caution, this result supports the hypothesis of the relationship between trait EI and the emotional indicators of children's drawings, which is a research area not yet studied in literature. In particular, the main hypothesis that the level of trait EI of a child and, consequently, traits pertaining to the regulation and expression of emotions can affect his or her way of representing the human figure in a drawing was confirmed. It is likely that trait EI acts as a predisposing factor in the adaptability of emotional experiences expressed by children through drawing. Thus, the DAP test could be an indirect (nonverbal) way of indicating the trait EI level. It could be argued that the trait EI construct is so well founded that it can also be detected through a graphical test. Moreover, drawing may facilitate young children's ability to talk about their emotional experiences in both clinical and educational contexts (Gross \& Hayne, 1998). Indeed, children may be reluctant or may lack the vocabulary to talk about their emotional status. Children's drawings offer a reliable projective tool that can be used to understand their feelings and difficulties, and trait EI has emerged as an important protective factor in the processes of resilience and adaptation (Keefer, Holden, \& Parker, 2013).

Research has suggested that children's drawings make connections that reveal the children's inner mental world (Cox, 1993). In line with this, inadequate emotional indicators may emerge as a consequence of emotional difficulties related to emotional disorders. Moreover, the construct of trait EI is particularly useful in capturing individual differences in emotional regulation (Mikolajczak, Nelis, Quoidbach, \& Hansenne, 2008). This consideration also has a practical implication. In particular, from a prevention and clinical perspective, screening children 
via the DAP test for emotional deficits related to a lower level of trait EI could assist providers

(e.g., teachers and school psychologists) in recognizing individuals who are vulnerable to psychological disorders and to arrange for early emotional support. Therefore, increasing our awareness of the developmental dynamics of children's trait EI has important practical implications, particularly with respect to programs and policies addressing children's emotional well-being.

\section{Conclusions}

This work represents an initial investigation of the relationship between trait EI and Koppitz's (1968) emotional indicators in children's drawings. However, the current research has some limitations that should be addressed in future studies.

First of all, the results are limited with respect to the convenience sample and the sociocultural context related to the school in which the survey was administered. For instance, the results are based on a relatively small and non-representative sample of Italian children. Because the current sample possibly influenced the generalisability of these findings, results should be treated with caution, and careful reflection is needed in their interpretation. Moreover, because children's drawings are partially reflective of their culture (La Voy et al., 2001), the results of this study are not generalised to children in other countries having different ethnic, social, and educational contexts. Future investigations should replicate these results in larger samples and in cross-cultural settings. To our knowledge, there are no patterns in cross-cultural studies, and more cultural research might identify emotional indicators that reflect true emotions in children versus cultural norms (Skybo et al., 2007).

Second, our study relies on cross-sectional and self-reported data, which always have critical issues in terms of accuracy. We cannot know, for example, how the dimensions we investigated unfold and develop over time, or the degree to which children's perceptions of the variables we measured are actually good reflections of their behaviours. Further studies would 
benefit from examining this issue by means of longitudinal investigation designs, which would help to shed new light on understanding the complexity of trait EI development.

Finally, the results of our work are necessarily limited to the instrument we chose. We are aware that although human figure drawings are well known and widely used in children's clinical investigations, as a screening or supplementary instrument during the diagnostic process, there is controversial evidence for the reliability and validity of such assessments, so more empirical data regarding the DAP test as a psychological measure is needed. However, the DAP test can be influenced by children's emotional attitudes toward the topics depicted (Thomas \& Jolley, 1998). It should be noted that this work specifically focused on the link between trait EI and Koppitz's (1968) emotional indicators emerging in the DAP test. Thus, we can derive some useful and valid information from these drawings when rendered by children, especially when the test is used along with other assessment tests, such as the TEIQue, but we should not rely on it to make strong inferences about specific personality features.

Notwithstanding these limitations, which lead to viewing the present findings as preliminary and interpreted with caution until they are replicated, the results of this research provide important information for the study of trait EI during childhood, in particular for scholars interested in exploring this construct using the DAP test. Human figure drawing is a particularly useful assessment tool: It is quick, inexpensive, and nonthreatening to children. Among its other advantages, it is easy to administer (only about 15-30 minutes plus a few minutes of inquiry), helps children who are anxious when taking tests, and is relatively culturefree. The use of a nonverbal, nonthreatening task to evaluate emotional indicators is supposed to eliminate possible sources of bias by reducing variables such as primary language, verbal skills, communication disabilities, and sensitivity to working under pressure, in an effort to understand the causal nexus between trait EI and health-related criteria. Thus, school-based research could benefit from graphic techniques as a tool of investigation less closely related to the clinical setting. 
Moreover, the results presented in this article have some relevant implications for school

psychologists and educational practice, which should be noted. In view of data highlighting that trait EI, connected to adequate emotional expression and regulation, is an important resource and a protective factor for psychological health, pupil assessment programs, as well as school psychology services, should therefore include this dimension in their action routines. In addition, it would be important to inform and train teachers on the formal and content aspects of children's drawings to enable them to provide graphic techniques as an educational strategy (e.g., group and laboratory activities using the DAP test), aimed at increasing pupils' EI and to support positive social relations in the class.

Much remains unknown about the developmental dynamics of children's subjective trait EI self-concepts, an area that is gaining increasing relevance for psychological well-being. The current study contributes to the efforts on the programs that best support positive emotional development in children. 


\section{References}

Abo Elella, E., Hassan, G. A., Sabry, W., Hendawy, H., Shorub, E., Zyada, F., \& Medany, O. (2017). Trait emotional intelligence in a sample of Egyptian children with Attention Deficit Hyperactivity Disorder. Child and Adolescent Mental Health, 22(4), 216-223.

Agnoli, S., Mancini, G., Pozzoli, T., Baldaro, B., Russo, P. M., \& Surcinelli, P. (2012). The interaction between emotional intelligence and cognitive ability in predicting scholastic performance in school-aged children. Personality and Individual Differences, 53(5), 660665.

Andrei, F., Mancini, G., Baldaro, B., Trombini, E., \& Agnoli, S. (2014). A systematic review on the Predictive Utility of the Trait Emotional Intelligence Questionnaire (TEIQue). BPAApplied Psychology Bulletin, 62(271).

Andrei, F., Siegling, A. B., Aloe, A. M., Baldaro, B., \& Petrides, K. V. (2016). The incremental validity of the Trait Emotional Intelligence Questionnaire (TEIQue): A systematic review and meta-analysis. Journal of Personality Assessment, 98(3), 261-276. doi: 10.1080/00223891.2015.1084630

Andrew, C. (2008). A Dictionary of Psychology (3rd Ed.). Oxford University Press. ISBN 9780199534067.

Barbaranelli, C., Caprara, G. V., Rabasca, A., \& Pastorelli, C. (2002). A questionnaire for measuring the Big Five in late childhood. Personality and Individual Differences, 34, 645654.

Bekhit, N. S., Thomas, G. V., \& Jolley, R. P. (2005). The use of drawing for psychological assessment in Britain: Survey findings. Psychology and Psychotherapy: Theory, Research and Practice, 78(2), 205-217. 
Buck, J. N. (1948). The H-T-P technique, a qualitative and quantitative method. Journal of Clinical Psychology, 4, 317-396.

Buck, J. N. (1981). The House-Tree-Person technique: A revised manual. Western Psychological Services, Los Angeles.

Costa, P. T., \& McCrae, R. R. (1992). Four ways five factors are basic. Personality and Individual Differences, 13(6), 653-665.

Cox, M. V. (1993). Children's drawings of the human figure. Hove, UK: Erlbaum.

Fernandez-Berrocal, P., \& Ruiz, D. (2008). Emotional intelligence in education. Electronic Journal of Research in Educational Psychology, 15, 2.

Frederickson, N., Petrides, K. V., \& Simmonds, E. (2012). Trait emotional intelligence as a predictor of socioemotional outcomes in early adolescence. Personality and Individual Differences, 52(3), 323-328.

Goldberg, L. R. (1993). The structure of phenotypic personality traits. American Psychologist, 48: 26-34. doi:10.1037/0003-066x.48.1.26

Goodenough, F. (1926). Measurement of intelligence by drawings. New York: World Book Co.

Gross, J. J. (2015). Emotion regulation: Current status and future prospects. Psychological Inquiry, 26(1), 1-26.

Gross, J., \& Hayne, H. (1998). Drawing facilitates children's verbal reports of emotionally laden events. Journal of Experimental Psychology: Applied, 4(2), 163-179. doi: 10.1037/1076-898X.4.2.163

Hammer, E. F. (1958). The clinical application of projective drawings. Charles C. Thomas, Springfield, Illinois. 
Hansenne, M., \& Legrand, J. (2012). Creativity, emotional intelligence, and school performance in children. International Journal of Educational Research, 53, 264-268.

Jellesma, F. C., Rieffe, C., Meerum Terwogt, M., \& Westenberg, P. M. (2011). Children's sense of coherence and trait emotional intelligence: A longitudinal study exploring the development of somatic complaints. Psychology and Health, 26(3), 307-320.

Keefer, K. V., Holden, R. R., \& Parker, J. D. (2013). Longitudinal assessment of trait emotional intelligence: measurement invariance and construct continuity from late childhood to adolescence. Psychological Assessment, 25(4), 1255.

Kokkinos, C. M., \& Kipritsi, E. (2012). The relationship between bullying, victimization, trait emotional intelligence, self-efficacy and empathy among preadolescents. Social Psychology of Education, 15(1), 41-58.

Koppitz, E. (1984). Psychological evaluation of human figure drawings by middle school pupils. Orlando: Grune and Stratton.

Koppitz, E. M. (1968). Psychological evaluation of children's human figure drawings. New York: Grune and Stratton.

La Voy, S. K., Pedersen, W. C., Reitz, J. M., Brauch, A. A., Luxenberg, T. M., \& Nofsinger, C. C. (2001). Children's drawings: A cross-cultural analysis from Japan and the United States. School Psychology International, 22(1), 53-63.

Laborde, S., Lautenbach, F., Allen, M. S., Herbert, C., \& Achtzehn, S. (2014). The role of trait emotional intelligence in emotion regulation and performance under pressure. Personality and Individual Differences, 57, 43-47.

Levy, S. (1950). Figure drawing as a projective test. Projective psychology: Clinical approaches to the total personality, 257-297. Knopf: New York. 
Lilienfield, S. O., Wood, J. M., \& Garb, H. N. (2000). Scientific status of projective techniques. Psychological Science in the Public Interest, 1, 27-66.

Machover, K. (1949). Personality projection: in the drawing of a human figure. Springfield, IL: Charles C. Thomas Publisher.

Machover, K. (1953). Human figure drawings of children. Journal of Projective Techniques, 17(1), 85-91.

Mancini, G., Andrei, F., Mazzoni, E., Biolcati, R., Baldaro, B., \& Trombini, E. (2017). Brief report: Trait emotional intelligence, peer nominations, and scholastic achievement in adolescence. Journal of Adolescence, 59, 129-133.

Martins, A., Ramalho, N., \& Morin, E. (2010). A comprehensive meta-analysis of the relationship between emotional intelligence and health. Personality and Individual Differences, 49, 554e564.

Mavroveli, S., \& Sánchez- Ruiz, M. J. (2011). Trait emotional intelligence influences on academic achievement and school behaviour. British Journal of Educational Psychology, 81(1), 112-134.

Mavroveli, S., Petrides, K. V., Sangareau, Y., \& Furnham, A. (2009). Exploring the relationships between trait emotional intelligence and objective socio- emotional outcomes in childhood. British Journal of Educational Psychology, 79(2), 259-272.

Mavroveli, S., Petrides, K. V., Shove, C., \& Whitehead, A. (2008). Investigation of the construct of trait emotional intelligence in children. European child \& adolescent psychiatry, 17(8), 516-526.

Mayer, J. D. (2008). Human Abilities: Emotional Intelligence. Annual Review of Psychology, 59: 507-536. doi:10.1146/annurev.psych.59.103006.093646 
Mikolajczak M., Nelis D., Quoidbach J., Hansenne M. (2008). If you can regulate sadness, you can probably regulate shame: impact of emotional intelligence on emotion regulation and coping efficiency across discrete emotions. Personality and Individual Differences 44, 1356-1368 10.1016/j.paid.2007.12.004

Murstein, B. (1965). Handbook of projective techniques. New York, NY: Basic Books Inc. Pedhazur, E. J., \& Pedhazur Schmelkin, L. P. (1991). Measurement, design, and analysis: An integrated approach. Hillsdale: Erlbaum.

Pérez-González, J. C., \& Sanchez-Ruiz, M. J. (2014). Trait emotional intelligence anchored within the Big Five, Big Two and Big One frameworks. Personality and Individual Differences, 65, 53-58.

Petrides, K. V., \& Furnham, A. (2003). Trait emotional intelligence: Behavioural validation in two studies of emotion recognition and reactivity to mood induction. European Journal of Personality, 17(1), 39-57. doi:10.1002/per.466

Petrides, K. V., Frederickson, N., \& Furnham, A. (2004). The role of trait emotional intelligence in academic performance and deviant behavior at school. Personality and Individual Differences, 36(2), 277-293.

Petrides, K. V., Furnham, A., \& Frederickson, N. (2004). Emotional intelligence. Psychologist, 17(10), 574-577.

Petrides, K. V., Furnham, A., \& Mavroveli, S. (2007). Trait emotional intelligence: Moving forward in the field of EI. Emotional intelligence: Knowns and unknowns, 151-166.

Petrides, K. V., Mikolajczak, M., Mavroveli, S., Sanchez-Ruiz, M. J., Furnham, A., \& PérezGonzález, J. C. (2016). Developments in trait emotional intelligence research. Emotion Review, 8(4), 335-341. 
Petrides, K.V. \& Furnham, A. (2000). On the dimensional structure of emotional intelligence. Personality and Individual Differences, 29, 313-320. doi: 10.1016/S01918869(99)00195-6

Petrides, K.V. \& Furnham, A. (2001). Trait emotional intelligence: Psychometric investigation with reference to established trait taxonomies. European Journal of Personality, 15, 425-448. doi:10.1002/per.416

Petrides, K.V.; Pita, R.; Kokkinaki, F. (2007). The location of trait emotional intelligence in personality factor space. British Journal of Psychology, 98: 273-289.

doi:10.1348/000712606x120618

Poulou M. S. (2014). How are trait emotional intelligence and social skills related to emotional and behavioural difficulties in adolescents? Educational Psychology, 34, 3, pp. 354-66.

Resurrección, D. M., Salguero, J. M., \& Ruiz-Aranda, D. (2014). Emotional intelligence and psychological maladjustment in adolescence: A systematic review. Journal of Adolescence, 37(4), 461-472.

Russo, P. M., Mancini, G., Trombini, E., Baldaro, B., Mavroveli, S., \& Petrides, K. V. (2012). Trait emotional intelligence and the Big Five: A study on Italian children and preadolescents. Journal of Psychoeducational Assessment, 30(3), 274-283.

Schutte, N. S., \& Malouff, J. M. (2016). Comment on developments in trait emotional intelligence research: A broad perspective on trait emotional intelligence. Emotion Review, 8(4), 343-344.

Scott, L. (1981). Measuring intelligence with the Goodenough-Harris drawing test. Psychological Bulletin, 89(3), 483-505. 
Skybo, T., Ryan-Wenger, N., \& Su, Y. H. (2007). Human figure drawings as a measure of children's emotional status: Critical review for practice. Journal of Pediatric Nursing, 22(1), 15-28.

Thomas, G. V., \& Jolley, R. P. (1998). Drawing conclusions: A re- examination of empirical and conceptual bases for psychological evaluation of children from their drawings. British Journal of Clinical Psychology, 37(2), 127-139.

van der Linden, D., Schermer, J. A., de Zeeuw, E., Dunkel, C. S., Pekaar, K. A., Bakker, A. B., ... Petrides, K. V. (2018). Overlap Between the General Factor of Personality and Trait Emotional Intelligence: A Genetic Correlation Study. Behavior Genetics, 48(2), 147-154. doi: 10.1007/s10519-017-9885-8

Weiner, I., \& Greene, R. (2008). Handbook of personality assessment. Hoboken, NJ: John Wiley and Sons.

Zeidner, M., \& Matthews, G. (2016). Ability emotional intelligence and mental health: Social support as a mediator. Personality and Individual Differences, 99, 196-199.

Zeidner, M., Roberts, R. D., \& Matthews, G. (2008). The science of emotional intelligence: Current consensus and controversies. European Psychologist, 13(1), 64-78. 
544 Table 1. Correlations between BFQ personality dimensions, trait EI and DAP test.

1

\begin{tabular}{l|llllllllll}
\multicolumn{1}{c}{} & Measures & M & DS & 1 & 2 & 3 & 4 & 5 & 6 & 7 \\
\hline 1 & BFQE & 43.91 & 8.59 & - & & & & & & \\
2 & BFQA & 55.51 & 9.00 & $.33^{* *}$ & - & & & & \\
3 & BFQC & 53.74 & 7.61 & $.27^{* *}$ & $.35^{* *}$ & - & & & \\
4 & BFQI & 45.98 & 10.37 & .04 & $-.40^{* * *}$ & $-.21^{*}$ & - & & \\
5 & BFQM & 47.20 & 7.85 & $.24 *$ & .11 & $.32^{* *}$ & .03 & - & \\
6 & TEI & 3.65 & 0.33 & $.30^{* *}$ & $.44^{* * *}$ & $.46^{* * *}$ & $-.49^{* * *}$ & $.27 * *$ & - & \\
7 & DAP & 9.89 & 2.29 & .13 & .06 & $.29^{* *}$ & -.05 & .06 & $.32 * *$ & -
\end{tabular}

Note. $\mathrm{BFQE}=$ Energy $/$ Extraversion $; \mathrm{BFQA}=$ Agreeableness $; \mathrm{BFQC}=$ Conscientiousness $; \mathrm{BFQI}=$ Emotional Instability; BFQM = Mind Openness; TEI = trait EI global score; DAP = drawing emotional indicators.

$* * * p<.001 . * * p<.01 . * p<.05$ 
Table 2. Hierarchical Regression Analysis on BFQ-C and TEIQue-CF.

\begin{tabular}{lcc}
\hline & \multicolumn{2}{c}{ BFQ TEI } \\
\cline { 2 - 3 } & Step 1 & Step 2 \\
\hline BFQ-E & .08 & .01 \\
BFQ-A & -.07 & -.11 \\
BFQ-C & $.30^{*}$ & .22 \\
BFQ-I & -.01 & .14 \\
BFQ-M & -.04 & -.10 \\
TEI & - & $.36^{* *}$ \\
& & \\
$R^{2}$ & .09 & .16 \\
$\Delta R^{2}$ & - & $.07^{* *}$ \\
$F$ & 1.53 & $2.45^{*}$ \\
\hline
\end{tabular}

Note $. \mathrm{BFQE}=$ Energy/Extraversion; $\mathrm{BFQA}=$ Agreeableness $; \mathrm{BFQC}=$ Conscientiousness $; \mathrm{BFQI}=$ Emotional Instability; BFQM = Mind Openness; TEI = trait EI global score.

$* * * p<.001 . * * p<.01 . * p<.05$ 
Ref.: Ms. No. ISCI-D-18-00019 Child Indicators Research

Saturday, September 1, 2018

Dear Editor,

I am enclosing a revised version of the manuscript entitled "Trait Emotional Intelligence and Draw-APerson emotional indicators: A first study on Italian 8 years old children" to be considered for publication in Child Indicators Research.

The manuscript is 25 pages long and includes 2 Tables. The total length of the manuscript is 6516 words (including References and Tables).

Minor revisions required by the Reviewer \#1 are yellow-highlighted in the manuscript.

I wish to thank the Editor-in-Chief for the very thorough and prompt review process.

Thanks in advance for your kind attention,

Giacomo Mancini 


\section{Reply to Reviewers' comments:}

I wish to thank the Reviewers for suggestions and comments to the paper.

\section{Reviewer \#1:}

The authors have improved the manuscript. However, there are some considerations:

- In instruments, what is the scale that measures The Big Five Questionnaire-Children?

Author: I have added the required measurement scale in the 'Measures' section.

- Regarding results, as there is almost no relation among DAP and FBQ dimensions, I believe that authors should inform this evidence after the phrase: "Significant positive associations also emerged between DAP emotional indicators and both Conscientiousness and trait EI" in the 'Results' section.

Author: I have included the required evidence in the 'Results' section at the point indicated by the Referee.

- Tables 1 and 2 are presented twice.

Author: Perhaps an additional file was accidentally attached to the submission. In the current version of the manuscript the references of the tables ("INSERT TABLE 1/2 HERE") are indicated in the text (pages 10 and 11) and the whole tables are reported only once on the last two pages (24 and 25).

I hope the authors find the comments helpful in the revision of this paper.

Author: Thank you for the helpful comments.

\section{Reviewer \#3:}

The revised paper 'Trait Emotional Intelligence and Draw-A-Person Emotional Indicators: A First Study on 8-Year- 10 Old Italian Children' deals with an interesting topic.

I found the revised version of the paper well-structured and sufficiently clearly written.

Author: Thank you. 